\title{
PSYCHOPHYSIOLOGY OF TYPE A BEHAVIOR PATTERN: A CRITICAL ANALYSIS
}

\author{
Michael Myrtek and Mark W. Greenlee
}

\author{
(Received 16 January 1984; accepted in revised form 22 April 1984)
}

\begin{abstract}
Abstrac1-Based on an analysis of 45 studies recently reported in the literature and data from a psychophysiological investigation, the hypothesized physiological mechanisms underlying Type $\mathrm{A}$ behavior and the methods used to determine Type A behavior (e.g., Structured Interview, SI, and the Jenkins Activity Survey, JAS) are tested. After determining behavior typc with both the SI and JAS, subjects $(N=58$ physical-education students) participated in a laboratory/field experiment with two replications consisting of the following conditions: (1) rest, (2) mental arithmetic, (3) rcaction time test, (4) preparing and giving a speech, (5) Cold Pressor Test, (6) bicycle ergometric exercise, and (7) $1000 \mathrm{~m}$ run. Blood pressure, heart rate, stroke volume, cardiac output, ventricular ejection time, pulse volume amplitude, pulse transit time, pulse wave velocity, electrodermal activity, respiratory volume, oxygen uptake, and uric catecholamine levels were measured. Results of the analysis of the literature indicate that, with the exception of change scores on systolic blood pressure, mean differences on the physiological measures exhibited by Type A and B men are primarily not significant. The Structured Interview shows only a modest inter-rater reliability. The Jenkins Activity Survey demonstrates relatively low stability upon retest and fails to show sufficient internal consistency. Corrclations between these measures are low. No consistent differences on physiological measures could be found in our subjects based on behavior type (according to SI or JAS criteria), although the challenging conditions were selected to elicit Type A behavior. For our data, differences between Types $A$ and $B$ were also not found for systolic blood pressure, regardless of which behavioral assessment method was employed.
\end{abstract}

\section{INTRODLCTION}

Rosenman and Friedman were the first to describe the so-called Type A behavior pattern. In the Western Collaborative Group Study (WCGS; a prospective study designed to identify risk factors in coronary heart disease), Rosenman and his colleagues [1] showed that, after controlling for the effects of such classical risk factors as blood pressure, serum cholesterol levels, etc., men who exhibited the Type A behavior pattern were twice as likely to suffer coronary heart disease than were their Type B counterparts (i.e., men who fail to show such overt signs of Type A behavior as explosive speech, competitiveness, etc.).

Since these initial observations, a mass of studies has attempted to explore possible pathophysiological processes leading to coronary heart disease. Primary emphasis has been given to tonic and phasic physiological differences between Type $\mathbf{A}$ and $\mathbf{B}$ men. According to the review by Williams and co-workers [2], Type A men are apparently characterized by increased sympathetic activity manifested in stronger responses to various environmental stimuli. These authors contend that these enhanced responses are primarily exhibited in the cardiovascular system. Since the publication of this review, the number of empirical findings on this issue has risen so greatly that an overall account of the data has become difficult.

The present study, therefore, takes on the task of giving a critical, but fair, analysis of the empirical results of studies published between 1976 and 1982. Furthermore, findings on the reliability of and agreement between the Structured Interview

Present address: Forschungsgruppe Psychophysiologie, Dept. of Psychology, University of Freiburg, Schillhof 5, 7800 Freiburg, West Germany. 
(SI) and the Jenkins Activity Survey (JAS) are reviewed. In a second part of the study, we present findings of a multivariate psychophysiological investigation conducted in our laboratory with a student subject sample that explores the possible association between Type A behavior pattern and heightened sympathetic activity.

\section{Analysis of empirical results (reported between 1976-1982)}

A total of 45 investigations on the issue of physiological differences between Type $A$ and $B$ men was found with the help of a computer-assisted retrieval service (MEDLARS). These studies are denoted in the references at the end of this paper. In addition, the inter-rater reliability of the Structured Interview and the agreement between categorization based on the SI and the JAS are considered. The studies used for this aspect of the analysis are listed separately in the references. Further details concerning the subject samples used, the physiological rest, strain and changes scores employed, and the methods used to assess behavior type may be found in Myrtek [3]. Here, we limit ourselves to summarizing the results concerned with the effect of behavior type on physiological responses.

Table I shows the physiological variables used in the studies analyzed here (left column). The type of data used (i.e., rest values, $R$, strain values, $S$, or change scores, C) are also given. The number of studies that employed the variable in question is given in the next column. Of this total, the number using students as subjects is further shown. In the next three columns, the number of studies that used one of the three behavior typing methods (Structured Interview, SI, Jenkins Activity Survey, JAS, and the Matthews Youth Test for Health, My) is given. The next two columns give the number of test results that were significant at the $5 \%$ level, where Type A men exhibited higher values (At) or where Type A men showed lower values (A $\downarrow$ ). In the final column, the number of test results that failed to reach the $5 \%$ significance level is presented. It is not possible here to give more details (e.g., mean values or exact significant levels) as this would greatly exceed space limitations. For more details see the study by Myrtek [3].

As can be seen in Table I, most of the studies employed only blood pressure and/or heart rate as physiological variables. Findings for other variables are, unfortunately, few. About $60 \%$ of the studies in question here used students as subjects. To determine behavior type, the SI was employed $56 \%$, and the JAS, $39 \%$ of the time.

The hypothesis of an enhanced sympathetic activity in Type A men implies that these men should exhibit (1) higher blood pressure values, (2) higher heart rate, (3) lower pulse volume amplitude, and (4) a shorter pulse transit time at rest and during challenge. Furthermore, for electrodermal activity, a higher frequency of skin conductance responses, shorter latencies, and a higher conductance level are to be expected. Type A men should also exhibit higher uric catecholamine levels as a result of increased sympathetic activity.

Table I (right column) shows, however, that the number of test results that fail to reach the $5 \%$ significance level is clearly in the majority. Even for change scores on systolic blood pressure, where one would expect Type A men to exhibit clear-cut differences, only 16 of a total of 38 tests (i.e., $42 \%$ ) are significant. For all other variables, though some tendencies may be evident in favor of the hypothesis (i.e., heart rate change scores, 5 of 37 , and skin conductance level during strain, 3 of 3 
TABLE I.-Results OF THE ANALYSIS OF THE LITERATURE PUBLISHED BETWEEN 1976 AND 1982. FOR EXPLANATION SEE TEXT

\begin{tabular}{|c|c|c|c|c|c|c|c|c|c|}
\hline \multirow{2}{*}{ Variables } & & \multicolumn{2}{|c|}{ N Studies } & \multicolumn{3}{|c|}{ Method } & \multicolumn{3}{|c|}{ Main effects } \\
\hline & & Tot. & Stu. & SI & JAS & My & A $\uparrow$ & At & ns \\
\hline \multirow[t]{3}{*}{ Blood pressure systolic } & $\mathrm{R}$ & 23 & 13 & 12 & 10 & 1 & 3 & 1 & 28 \\
\hline & $\mathrm{S}$ & 9 & 7 & 5 & 4 & 0 & 3 & 1 & 24 \\
\hline & $\mathrm{C}$ & 18 & 9 & 13 & 4 & 1 & 16 & 0 & 22 \\
\hline \multirow[t]{3}{*}{ Blood pressure diastolic } & $\mathbf{R}$ & 22 & 13 & 11 & 10 & 1 & 1 & 0 & 28 \\
\hline & $\mathrm{S}$ & 9 & 7 & 5 & 4 & 0 & 2 & 0 & 24 \\
\hline & C & 17 & 9 & 12 & 4 & 1 & 5 & 0 & 32 \\
\hline \multirow[t]{3}{*}{ Heart rate } & $\mathbf{R}$ & 22 & 15 & 10 & 11 & 1 & 1 & 2 & 25 \\
\hline & $\mathrm{S}$ & 12 & 10 & 4 & 8 & 0 & 4 & 0 & 26 \\
\hline & $\mathrm{C}$ & 18 & 11 & 10 & 7 & 1 & 5 & 1 & 31 \\
\hline \multirow[t]{3}{*}{ Heart rate variability } & $\mathbf{R}$ & 5 & 2 & 4 & 0 & 1 & 2 & 0 & 4 \\
\hline & $\mathrm{S}$ & 1 & 1 & 1 & 0 & 0 & 0 & 0 & 1 \\
\hline & C & 6 & 3 & 5 & 0 & 1 & 0 & 0 & 14 \\
\hline \multirow[t]{3}{*}{ Pulse vol. ampl./blood flow } & $\mathrm{R}$ & 4 & 4 & 2 & 2 & 0 & 1 & 0 & 3 \\
\hline & $\mathrm{S}$ & 4 & 4 & 2 & 2 & 0 & 5 & 0 & 6 \\
\hline & $\mathrm{C}$ & 4 & 3 & 3 & 1 & 0 & 1 & 0 & 5 \\
\hline \multirow[t]{3}{*}{ Pulse transit time } & $\mathrm{R}$ & 1 & 0 & 0 & 1 & 0 & 0 & 0 & 1 \\
\hline & $\mathrm{S}$ & 0 & - & - & - & - & - & - & - \\
\hline & $\mathrm{C}$ & 2 & 1 & 0 & 2 & 0 & 0 & 0 & 5 \\
\hline \multirow[t]{3}{*}{ EDA, SCR frequency } & $\mathbf{R}$ & 4 & 3 & 3 & 0 & 1 & 0 & 0 & 5 \\
\hline & $\mathrm{S}$ & 4 & 3 & 4 & 0 & 0 & 3 & 0 & 3 \\
\hline & C & 5 & 3 & 3 & 1 & 1 & 0 & 0 & 6 \\
\hline \multirow[t]{3}{*}{ EDA, SCR latency } & $\mathrm{R}$ & 1 & 0 & 0 & 0 & 1 & 0 & 0 & 2 \\
\hline & $\mathrm{S}$ & 0 & - & - & - & - & - & - & - \\
\hline & C & 1 & 0 & 0 & 0 & 1 & 0 & 0 & 2 \\
\hline \multirow[t]{3}{*}{ EDA, skin conduct. level } & $\mathbf{R}$ & 2 & 1 & 1 & 1 & 0 & 0 & 0 & 2 \\
\hline & $S$ & 1 & 1 & $\mathbf{1}$ & 0 & 0 & 3 & 0 & 0 \\
\hline & $\mathrm{C}$ & 1 & 0 & 0 & 1 & 0 & 0 & 0 & 1 \\
\hline \multirow[t]{3}{*}{ Respiratory rate } & $\mathbf{R}$ & 1 & 0 & 0 & 1 & 0 & 0 & 0 & 1 \\
\hline & $\mathrm{S}$ & 0 & - & - & - & - & - & - & - \\
\hline & $\mathrm{C}$ & 1 & 0 & 0 & 1 & 0 & 0 & 0 & 1 \\
\hline \multirow[t]{3}{*}{ Breathing depth } & $\mathbf{R}$ & 1 & 0 & 0 & 1 & 0 & 0 & 0 & 1 \\
\hline & $S$ & 0 & - & - & - & - & - & - & - \\
\hline & $\mathrm{C}$ & 1 & 0 & 0 & 1 & 0 & 0 & 0 & 1 \\
\hline \multicolumn{2}{|l|}{ Maximal work load $\left(\mathrm{VO}_{2}, \mathrm{~W}\right)$} & 3 & 1 & 2 & 1 & 0 & 0 & 1 & 6 \\
\hline \multirow{2}{*}{\multicolumn{2}{|c|}{$\begin{array}{l}\text { Epinephrine excretion } \\
\text { Norepinephrine excretion }\end{array}$}} & 6 & 4 & 3 & 3 & 0 & 2 & 1 & 10 \\
\hline & & 7 & 5 & 3 & 4 & 0 & 1 & 0 & 14 \\
\hline \multicolumn{2}{|l|}{$\begin{array}{l}\text { Performance (mental } \\
\text { arithmetic etc.) }\end{array}$} & 18 & 17 & 8 & 10 & 0 & 8 & 1 & 36 \\
\hline
\end{tabular}

reach the $5 \%$ significance level), overall, non-significant results prevail. Contrary to the hypothesis of enhanced sympathetic activity in Type A men, 5 of 11 test results for pulse volume amplitude show greater finger blood flow in Type A's during strain. Note also the lack of significant results for epinephrine and norepinephrine ( 4 from a total of 28 tests, one of which is contrary to expectation).

\section{Reliability of and agreement between SI and JAS}

The stability of the Structured Interview (SI) is, to a great extent, unknown. Rosenman [4] singly reports that after a period of 12 to 20 months, $80 \%$ of subjects 
in the WCGS "had a similar categorial assessment"' (p. 56). Other reports on stability were not evident in the literature. We also compared estimates of interrater reliability: in the studies considered here, $70 \%$ agreement was found, on average, when all 4 categories were considered, and $78 \%$ when only the $\mathrm{A} / \mathrm{B}$ dichotomy was employed. Considering that for most of these studies $60 \%$ of all subjects were classified as Type A (i.e., A1 or A2), the increment over chance levels is modest.

Jenkins, Zyzanski and Rosenman [5] report a stability coefficient of 0.66 for the A/B scale of the JAS-B (subject sample from WCGS, $N=2800$, retest after oneyear interval). For a sample of middle-aged civil servants, Johnston and Shaper [6] report a moderately high stability coefficient of 0.79 with a retest interval of 17 and 34 weeks. In our investigation with physical-education students, a more modest coefficient of 0.61 (JAS-T, retest after onc-year) was found. Myrtek, Schmidt and Schwab [7] conducted item analyses for the JAS-B and JAS-T forms with different subject samples. An average part/whole correlation between 0.07 and 0.12 was found for the A/B scale of the JAS-B form. The internal consistency based on 10 items (Cronbach's alpha) varied between 0.41 and 0.59. Part/whole correlations varying between 0.19 and 0.24 and an internal consistency between 0.70 and 0.76 were found for the $\mathrm{A} / \mathrm{B}$ scale of the JAS-T form. The more favorable psychometric properties of the JAS-T form appear to be caused by the different item weighting used for these forms.

Several authors have reported correlation coefficients between the SI and JAS methods. After transforming these coefficients using Fisher's $z$ transformation, we calculated weighted mean correlation coefficients between the SI and the A/B scale of the JAS. The average correlation is 0.34 , which means that the common variance shared by these methods is merely $11 \%$. Myrtek, Schmidt and Schwab [7] further report correlations between the SI and the JAS-B form $(r=0.04$, for $N=209$ and $r=0.12$, for $N=78)$, as well as between the SI and the IAS-T form $(r=0.13$, for $N=78$ and $r=0.23$, for $N=58$ ).

\section{METHOD}

\footnotetext{
Subjects

Male physical-education students $(N-58$; mean age $=23.3, \mathrm{sD}=2.3$ ) frec of any obvious signs of illness were paid for their participation in the experiment. Compared to a subject sample of other university students of the same age $(N=61)$, these students exhibited a considerably higher level of physical fitness, as indicated in maximal oxygen uptake $\left(3.81 \mathrm{~min}^{1} \mathrm{vs} 2.91 \mathrm{~min}{ }^{1}\right)$, although the slandard deviations do not differ by much ( $\mathrm{SD}=0.68 \mathrm{vs} \mathrm{SD}=0.55$, respectively).

\section{Procedures}

After initial instructions and behavior lyping-based on the Struclured Intervicw and the Jenkins Activity Survey - subjects were examined twice in our laboratory and wice in the ficld. licld measures were conducted at the athletic stadium of the University within a period of 2 months. $\wedge$ third laboratory and field examination was conducted after a period of 6 weeks to assess the eflect ol psychoplysiologicat relaxation training. Twelve months after the initial examination, a final assessment was made 10 test the stability of the behavior type. The following experimental conditions were employed: (1) initial and final rest phase, (2) relaxation phase, (3) mental arithmetic during acoustic distraction, (4) reaction time lest, (5) preparing and giving a speech, (6) Cold Pressor test, and (7) bicycle ergometric exercise (100 $\mathrm{W}$, relative steady state). Following ergomelric excrcise, the first four min of recovery were also recorded. Our field measures were taken at rest prior to a competition, approaching the stadium, the actual $1000 \mathrm{~m}$ run, and the sixth min of recovery from the run. To enhance the competitive nature of the various lasks, monetary incentives were given dependent on performance. These challenges were selected so that the intensity and challenging nature of the tasks difter.
} 


\section{Apparatus}

A 16-channel polygraph (Hellige $\mathrm{GmbH}$, Freiburg) was used to record physiological data. Ihis was controlled by a IBM 1130 computer. A mercury manometer was used to measure blood pressure (BP). Systolic blood pressure was determined at the occurrence of the first Korotkoff sound, whereas diastolic blood pressure was based on the point of distinct muffling. An impedance cardiograph (Model 400, Instrumentation for Medicine, Inc.) assessed impedance cardiography (ICG). Pulse volume amplitude (PVA) was measured using a pncumatic transducer (Boucke pressure transducer) on the middle finger of the right hand. Pulse transit time (PTT) was assessed based on the latency between the $\mathrm{R}$ wave in the ICG and the arrival of the pulse wave at the linger. Electrodermal activity was measured as skin conductance with a constant voltage using a Beckman 9842 coupler. Eye blink activity was recorded via electrodes positioned above and below the right eye. To assess respiratory rate we used a pneumatic system consisting of flexible tubes that were positioned across the chest and abdomen (Schwarzer model $Z$ 937). To assess oxygen uptake, we used the pneumotest system (Jaeger Inc., Würzburg), the $\mathrm{O}_{2}$ analyzer Oxytest (Jaeger, Inc.), and the $\mathrm{CO}_{2}$ analyzer Uras (Hartmann \& Braun, Co.). Ergometry was performed on a bicycle ergometer, which functioned independently of the number of revolutions and was braked with eddy current (Mijnhardt Co., The Netherlands).

In the ficld, heart rate (ECG chest leads) was recorded by a microprocessor-controlled system (M2P, Deutsche Versuchsanstalt für Luft-und Raumfahrt). Respiratory rate in the ficld was monitored with the Medilog system (Oxford, I.td.). Subjects carried both systems in a small rucksack, especially designed for this purpose.

Flurometric assessment of epinephrine and norepinephrine was made using the trihydroxyindole merhod (Bio-Rad Co., Munich). Statistical quality control was conducted with control urine from the same company.

During all experimental phases, subjects were asked to rate their subjective state on a 11 -step scalc. The subjective state experienced in the initial rest phase served as reference.

\section{Analysis of the data}

Since the resulting correlation between the SI and JAS proved to be low $(0.23)$, we analyze the effect of behavior type, as defined by these methods, separately. Two factorial analysis of varidnce tested the main effects, "Behavior Type" and "Examination Periods". For our present purposes, we only report the results of the "Behavior Iype" main effect. The change scores used in the analysis are the simple arithmetic differences between rest and strain values, as well as the autonomic lability score (ALS) according to Lacey [8], which considers possible dependency on initial values.

\section{Categorization of subjects}

Subjects were categorized into behavior types by employing the Structured Interview (SI) according to Rosenman [4] and Dembrowski [9]. Of a total of 58 subjects, 12 were classified as A1, 23 as A2, 11 as X, and 12 as B. Dr. W. I angosch, trained by Dr. Dembrowski, also independently assigned subjects to one of the 4 categories. The agreement between raters was $65 \%$ when all 4 categories were considered and $80 \%$ when only the $\mathbf{A} / \mathbf{B}$ dichotomy was used. The disagreement of raters did not exceed one step, e.g., if one rater scored a subject as $\mathrm{B}$, in case of disagreement, this subject was rated as $\mathrm{X}$ but not $\mathrm{A}$ l or $\wedge 2$.

Independent categorization based on questionnaire data was also conducted with the JAS-T form of the Jenkins Activity Survey. The German translation was provided by Dr T. H. Schmidt, Dept, of Psychosomatic Medicine, University of Cologne, who also calculated the subject's scores. The IAS scores ranged from 1 to 13 , with a standard deviation of 3.0. The mean, median and mode values were $6.4,6$, and 7 , respectively. There is no agreement in the literature as to how to assign subjects to either $\mathrm{A}$ or 13 groups. Since our distribution was normal, we assigned all subjects with a score of 6 or less 10 the $B$ group and subjects with 7 or more to the A group.

\section{RESULTS}

For our purposes here, we only report the results for the main effect "Bchavior Type'. Further details may be found in [3]. As in Table I, Table II shows the results of the tests of significance for the physiological variables used in our study (left column). The first two columns on the right depict the number of significant results

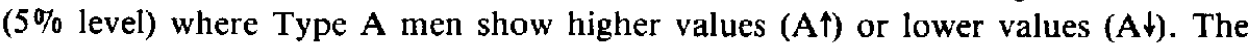
third column gives the number of tests that fail to reach the $5 \%$ level (NS). These values are based on behavioral typing with the Sl, whereas the last three columns give the same for results based on the JAS typing. Furthermore, we now show 
TABle II.-Results of PSychophysiological EXPERIMENT. For eXPLANations SEe TEXT

\begin{tabular}{|c|c|c|c|c|c|c|c|}
\hline \multirow{2}{*}{ Variables } & & \multicolumn{3}{|c|}{ SI } & \multicolumn{3}{|c|}{ JAS } \\
\hline & & $\mathrm{A} \uparrow$ & At & $\mathrm{ns}$ & $\mathrm{A}^{\dagger}$ & A $\downarrow$ & NS \\
\hline \multirow{4}{*}{ Blood pressure systolic } & $\mathbf{R}$ & 0 & 0 & 12 & 0 & 0 & 12 \\
\hline & S & 0 & 1 & 29 & 0 & 3 & 27 \\
\hline & D & 0 & 2 & 10 & 0 & 3 & 9 \\
\hline & $\mathrm{A}$ & 0 & 2 & 10 & 0 & 3 & 9 \\
\hline \multirow[t]{4}{*}{ Blood pressure diastolic } & $\mathrm{R}$ & 0 & 0 & 12 & 0 & 0 & 12 \\
\hline & S & 0 & 0 & 30 & 0 & 2 & 28 \\
\hline & D & 0 & 1 & 11 & 0 & 4 & 8 \\
\hline & A & 0 & 3 & 9 & 0 & 4 & 8 \\
\hline \multirow[t]{4}{*}{ Heart rate, means } & $\mathrm{R}$ & 0 & 0 & 12 & 0 & 0 & 12 \\
\hline & $\mathrm{S}$ & 0 & 0 & 31 & 0 & 0 & 31 \\
\hline & D & 0 & 0 & 12 & 1 & 2 & 9 \\
\hline & A & 0 & 0 & 12 & 0 & 2 & 10 \\
\hline \multirow[t]{4}{*}{ Heart rate, standard dev. } & $\mathrm{R}$ & 0 & 0 & 9 & 0 & 3 & 6 \\
\hline & $\mathrm{s}$ & 0 & 0 & 22 & 0 & 3 & 19 \\
\hline & D & 0 & 0 & 12 & 0 & 0 & 12 \\
\hline & A & 0 & 0 & 12 & 0 & 1 & 11 \\
\hline \multirow{4}{*}{ ICG, stroke volume } & $\mathrm{R}$ & 0 & 0 & 6 & 3 & 0 & 3 \\
\hline & $\mathrm{S}$ & 0 & 0 & 9 & 0 & 0 & 9 \\
\hline & D & 0 & 0 & 9 & 0 & 0 & 9 \\
\hline & A & 0 & 0 & 9 & 0 & 0 & 9 \\
\hline \multirow[t]{4}{*}{ ICG, cardiac output } & $\mathrm{R}$ & 2 & 0 & 4 & 2 & 0 & 4 \\
\hline & $\mathrm{S}$ & 0 & 0 & 9 & 0 & 0 & 9 \\
\hline & D & 0 & 0 & 9 & 0 & 0 & 9 \\
\hline & $A$ & 0 & 0 & 9 & 0 & 0 & 9 \\
\hline \multirow{4}{*}{ ICG, ventr. eject. time } & $\mathbf{R}$ & 1 & 0 & 5 & 0 & 0 & 6 \\
\hline & $\mathrm{S}$ & 0 & 0 & 9 & 0 & 0 & 9 \\
\hline & D & 0 & 0 & 9 & 0 & 0 & 9 \\
\hline & A & 0 & 0 & 9 & 0 & 0 & 9 \\
\hline \multirow[t]{4}{*}{ Pulse volume amplitude } & $\mathrm{R}$ & 0 & 0 & 6 & 0 & 0 & 6 \\
\hline & $\mathrm{S}$ & 0 & 0 & 12 & 0 & 0 & 12 \\
\hline & D & 0 & 0 & 12 & 0 & 0 & 12 \\
\hline & A & 1 & 0 & 11 & 0 & 0 & 12 \\
\hline \multirow[t]{4}{*}{ Pulse transit time } & $\mathrm{R}$ & 0 & 0 & 6 & 0 & 0 & 6 \\
\hline & $S$ & 0 & 0 & 12 & 0 & 0 & 12 \\
\hline & D & 0 & 0 & 12 & 1 & 0 & 11 \\
\hline & A & 0 & 0 & 12 & 1 & 0 & 11 \\
\hline \multirow[t]{4}{*}{ Pulse wave velocity } & $\mathrm{R}$ & 0 & 0 & 6 & 0 & 0 & 6 \\
\hline & S & 0 & 0 & 12 & 0 & 0 & 12 \\
\hline & D & 0 & 0 & 12 & 0 & 1 & 11 \\
\hline & A & 0 & 0 & 12 & 0 & 1 & 11 \\
\hline \multirow[t]{4}{*}{ EDA, skin conduct. level } & $\mathrm{R}$ & 2 & 0 & 4 & 0 & 0 & 6 \\
\hline & S & 1 & 0 & 11 & 0 & 0 & 12 \\
\hline & D & 0 & 0 & 12 & 0 & 0 & 12 \\
\hline & A & 0 & 0 & 12 & 1 & 0 & 11 \\
\hline \multirow{4}{*}{ EDA, SCR amplitude } & $\mathrm{R}$ & 0 & 0 & 6 & 0 & 0 & 6 \\
\hline & $\mathrm{S}$ & 0 & 0 & 12 & 0 & 0 & 12 \\
\hline & D & 0 & 0 & 12 & 1 & 0 & 11 \\
\hline & A & 0 & 0 & 12 & 1 & 0 & 11 \\
\hline \multirow[t]{4}{*}{ EDA, SCR frequency } & $\mathrm{R}$ & 0 & 0 & 6 & 0 & 0 & 6 \\
\hline & $\mathrm{S}$ & 0 & 0 & 12 & 0 & 1 & 11 \\
\hline & D & 0 & 0 & 12 & 0 & 0 & 12 \\
\hline & A & 0 & 0 & 12 & 0 & 1 & 11 \\
\hline
\end{tabular}


TABLE II-Continued

\begin{tabular}{|c|c|c|c|c|c|c|c|}
\hline \multirow{2}{*}{\multicolumn{2}{|c|}{ Variables }} & \multicolumn{3}{|c|}{ SI } & \multicolumn{3}{|c|}{ JAS } \\
\hline & & $\mathbf{A} \uparrow$ & $A \downarrow$ & ns & $A \uparrow$ & At & NS \\
\hline \multirow[t]{4}{*}{ Eye blink rate } & $\mathbf{R}$ & 0 & 0 & 6 & 0 & 0 & 6 \\
\hline & S & 0 & 0 & 12 & 0 & 0 & 12 \\
\hline & $\mathrm{D}$ & 0 & 2 & 10 & 0 & 1 & 11 \\
\hline & A & 0 & 0 & 12 & 0 & 0 & 12 \\
\hline \multirow[t]{4}{*}{ Eye blink amplitude } & $\mathbf{R}$ & 0 & 0 & 6 & 0 & 0 & 6 \\
\hline & $\mathrm{S}$ & 1 & 0 & 11 & 0 & 0 & 12 \\
\hline & D & 1 & 0 & 11 & 0 & 0 & 12 \\
\hline & A & 1 & 0 & 11 & 0 & 0 & 12 \\
\hline \multirow[t]{4}{*}{ Respiratory rate } & $\mathbf{R}$ & 0 & 0 & 12 & 3 & 0 & 9 \\
\hline & $\mathrm{S}$ & 0 & 0 & 30 & 2 & 0 & 28 \\
\hline & $\mathrm{D}$ & 0 & 1 & 11 & 0 & 3 & 9 \\
\hline & A & 0 & 0 & 12 & 0 & 3 & 9 \\
\hline \multirow[t]{2}{*}{ Tidal volume } & $\mathbf{R}$ & 0 & 0 & 3 & 0 & 1 & 2 \\
\hline & $\mathrm{S}$ & 0 & 0 & 9 & 0 & 0 & 9 \\
\hline \multirow[t]{2}{*}{ Respiratory minute vol. } & $\mathbf{R}$ & 0 & 0 & 3 & 1 & 0 & 2 \\
\hline & $\mathrm{S}$ & 2 & 0 & 7 & 0 & 0 & 9 \\
\hline \multirow[t]{2}{*}{ Respiratory quotient } & $\mathrm{R}$ & 0 & 0 & 3 & 1 & 0 & 2 \\
\hline & $\mathrm{S}$ & 0 & 0 & 9 & 0 & 0 & 9 \\
\hline \multirow[t]{2}{*}{ Oxygen uptake } & $\mathbf{R}$ & 0 & 0 & 3 & 0 & 0 & 3 \\
\hline & $\mathrm{S}$ & 2 & 0 & 7 & 0 & 0 & 9 \\
\hline \multirow[t]{2}{*}{ Oxygen equivalent } & $\mathbf{R}$ & 0 & 0 & 3 & 1 & 0 & 2 \\
\hline & $\mathbf{S}$ & 0 & 0 & 9 & 0 & 0 & 9 \\
\hline \multirow[t]{2}{*}{ Oxygen pulse } & $\mathrm{R}$ & 0 & 0 & 3 & 0 & 0 & 3 \\
\hline & $\mathrm{S}$ & 0 & 0 & 9 & 1 & 0 & 8 \\
\hline \multicolumn{2}{|l|}{ Maximal work load, watt } & 2 & 0 & 1 & 0 & 0 & 3 \\
\hline \multirow{2}{*}{\multicolumn{2}{|c|}{$\begin{array}{l}\text { Epinephrine excretion } \\
\text { Norepinephrine excretion }\end{array}$}} & 1 & 0 & 1 & 0 & 0 & 2 \\
\hline & & 0 & 0 & 2 & 0 & 0 & 2 \\
\hline \multicolumn{2}{|l|}{$1000 \mathrm{~m}$-race, performance } & 0 & 0 & 3 & 0 & 0 & 3 \\
\hline \multirow{3}{*}{\multicolumn{2}{|c|}{$\begin{array}{l}\text { Reaction time } \\
\text { Mental arithmetic task, performance } \\
\text { Mental arithmetic task, errors }\end{array}$}} & 0 & 0 & 3 & 0 & 0 & 3 \\
\hline & & 0 & 0 & 3 & 0 & 2 & 1 \\
\hline & & 0 & 0 & 3 & 0 & 0 & 3 \\
\hline \multicolumn{2}{|l|}{ Emotional state, tense } & 0 & 0 & 33 & 0 & 0 & 33 \\
\hline \multicolumn{2}{|l|}{ angry } & 0 & 0 & 33 & 0 & 0 & 33 \\
\hline \multicolumn{2}{|l|}{ insecure } & 0 & 0 & 33 & 0 & 0 & 33 \\
\hline \multicolumn{2}{|l|}{ cramped } & 0 & 0 & 33 & 0 & 0 & 33 \\
\hline \multicolumn{2}{|l|}{ illhumored } & 0 & 0 & 33 & 0 & 0 & 33 \\
\hline \multicolumn{2}{|l|}{ active } & 0 & 0 & 33 & 0 & 0 & 33 \\
\hline \multicolumn{2}{|l|}{ nervous } & 0 & 0 & 33 & 0 & 0 & 33 \\
\hline helpless & & 0 & 0 & 33 & 0 & 0 & 33 \\
\hline indifferent & & 0 & 0 & 33 & 0 & 0 & 33 \\
\hline competitive & & 0 & 0 & 33 & 0 & 0 & 33 \\
\hline annoying & & 0 & 0 & 33 & 0 & 0 & 33 \\
\hline
\end{tabular}

change scores first as simple arithmetic differences (D) and as autonomic lability scores (A). The large number of tests given here resulted from the several experimental conditions and the three complete repetitions.

Increased values on systolic blood pressure could not be substantiated by our data. On the contrary, all tests reaching significance levels indicate that Type A men show lower values on systolic blood pressure than their Type B counterparts. This trend is apparent for both methods of behavioral typing. Similar results are evident 
for heart rate and heart rate variability. For the SI method, no significant results are evident, whereas for the JAS method one comparison is significant in the expected direction and 11 in the opposite direction, the rest failing to reach significance levels.

Based on the JAS categorization, 3 of 6 tests are significant for stroke volume at rest in the expected direction and 2 of 6 for cardiac output at rest. Cardiac output also showed expected differences in 2 of 6 tests after men were typed according to the SI. These findings were not, however, consistent over the three examination periods, and are restricted to rest values. Results of tests for ventricular ejection time are only significant once for the SI typing. Compared to the number of tests that fail to reach significance levels, this finding could be a result of chance effects. The single significant finding for pulse volume amplitude, in the opposite direction of expectation, is probably also due to chance. Similarly, for pulse transit time only 2 tests reach significance levels: the simple difference between rest and strain and the autonomic lability score. These are also contrary to the hypothesis, since decreases in the pulse transit time should be shown by Type A men under strain. The same holds for pulse wave velocity where Type A men are expected to show increased change scores.

Based on the SI, Type A men tend to show a higher skin conductance level than their Type B fellows as expected. These findings fail, however, to be consistent over all three examination periods. In addition, the remaining EDA parameters do not support these findings. Of the 5 tests that reach significance levels, 2 are in the opposite direction for subjects typed with the JAS. Eye blink activity also fails to provide a consistent description of differences between behavior types.

Based on the JAS, Type A men exhibit higher respiratory rates at rest in 3 of 12 tests and under strain in 2 of 30 tests. In 3 of 12 tests, change scores on respiratory rate are significantly lower, the rest remaining insignificant. Thus, interpretation of these results are equivocal. For the other respiratory variables, Type $\mathbf{A}$ men fail to consistently differ from their Type B counterparts. In 2 of 9 tests, Type A men (SI criteria) show higher values on respiratory minute volume and oxygen uptake under strain, but fail to show differences at rest or on respiratory quotient. These differences in the expected direction probably have less to do with the $\mathrm{A} / \mathrm{B}$ behavior pattern and more to do with metabolic differences: Type A men (SI criteria) are, on average, $4 \mathrm{~kg}$ heavier than their Type B counterparts. This weight difference may increase their maximal work load (see Table II) and thus lead to higher oxygen uptakes and a corresponding higher respiratory minute volume during recovery. Based on the JAS criteria, results for rest values on respiratory minute volume, respiratory quotient, and oxygen equivalent are significant in the expected direction, but fail to be replicated in the second and third examinations.

Epinephrine excretion is significant in the first test and fails to reach significance in the second test for men typed according to the SI, whereas norepinephrene fails in both tests to reach significance levels. No test shows significant differences for men typed on the JAS. No difference is evident for performance on the $1000 \mathrm{~m}$ run and, contrary to expectation, in two of three tests Type A men (JAS criteria) perform worse than Type B's on the mental arithmetic task.

Not a single difference was found on the self-ratings of subjective state during the experiment. For the variables, tense, active and competitive, higher scores were expected to be found in Type A men, but failed to occur. 


\section{DISCUSSION}

The present study has explored hypothesized physiological differences between Type A and B men. The findings in the literature have been interpreted as evidence for an enhanced sympathetic activity and greater response tendencies in performance situations in Type A men. This increased activity is supposedly focussed on the cardiovascular system.

Our analysis of the literature published between 1976 and 1982 indicates that the significant findings in the expected direction are, with the exception of change scores on systolic blood pressure, in the small minority. The positive findings have been, to a great extent, over-interpreted. If one considers the possible studies that were either not submitted or rejected for publication because of "negative" results, the number of positive results probably does not exceed chance levels.

The findings of our own investigation fail to replicate differences on blood pressure and heart rate thought to be important in the literature on the Type A behavior pattern. The tests that do reach significance levels contradict the notion of increased sympathetic activity in Type A men. Findings for the remaining physiological variables employed primarily fail to show significant differences between behavior types. For every "positive" result shown in Table II there is nearly one significant result in the opposite direction, not to mention the majority of results that are not significant. Furthermore, no consistent differences are evident between the methods used to type men as either A or B.

Note that the laboratory and field challenges used in our investigation were selected so that, if any differences were evident between behavior types, they should be exhibited here. All of our challenges are competitive in nature, a requirement thought to be very important in the literature. The considerable differences evident between rest and strain scores confirm our contention that the challenges used here were experienced as such by our subjects. Furthermore, challenges in the field also fail to support the Type A hypothesis.

It may be argued that students, especially students of physical education, are not suitable for this type of research. There are, however, arguments against this view: (1) Physical-education students do not differ from other students regarding physiological reactivity or psychological variables, apart from the greater extent of physical fitness mentioned earlier. (2) The analysis of empirical results revealed that about $60 \%$ of all studies in the literature are conducted with students as subjects. (3) It is supposed that some components of Type A behavior may have a genetic basis [10]. It, therefore, seems even more unlikely that our subjects differ on behavior type from the normal population. (4) The distribution of SI assignment and JAS scores do not substantially differ from scores obtained in different subject samples.

The methods used to categorize subjects into the behavior types are also not above criticism. The results of our analysis of the literature indicate that the SI and JAS share only $11 \%$ common variance. Our own data show an even lower coefficient. Therefore, the SI and JAS appear to be primarily measuring different aspects of personality. The psychometric characteristics of these procedures also fail to be satisfactory: the inter-rater reliability of the SI only shows modest improvements over chance assignment, the stability of the SI is, to a great extent, unknown, and the stability of the JAS is only modest. In addition, the internal consistency of the 
JAS-B form is unacceptably low. In order to replicate the categorization given by the SI, certain aspects of reliability have apparently been ignored. Perhaps this would be acceptable if, indeed, the JAS accomplished the task of imitating the SI: our findings, and the findings of others fail, however, to support this claim.

In addition to the methodological weaknesses demonstrated by the procedures used to categorize subjects into behavior types, the results of the analysis of the literature and of our own study indicate that the hypothesized physiological differences between Type A and B persons remain, for the time being, missing.

Acknowledgements-This research was supported by the Deutsche Forschungsgemeinschaft. The authors would like to thank I. Trichtinger who conducted the Structured Interviews and Dr. W. Langosch who supervised the interviewing.

\section{REFERENCES}

1. Rosenman RH, Brand R.I, Jenkins CD, Friedman M, Straus R, Wurm M. Coronary heart disease in the Western Collaborative Group Study: final follow-up experience of $81 / 2$ years. $J \mathrm{Am} \mathrm{Med} \mathrm{Ass}$ $1975 ; 233: 872-877$.

2. Williams RB, Friedman M, Glass DC, Herd JA, Schneiderman N. Section summary: mechanisms linking behavioral and pathophysiological processes. In: Coronary Prone Behavior, pp. 120-128. (Edited by Dembroski TM, Weiss SM, Shields JL, Haynes SG, Feinleib M). New York: Springer, 1978.

3. Мүгтек M. Typ-A-Verhalten. Untersuchungen und Literaturanalysen unter besonderer Berücksichtigung der psychophysiologischen Grundlagen. München: Minerva, 1983.

4. Rosenman RH. The interview method of assessment of the coronary-prone behavior pattern. In: Coronary Prone Behavior (Edited by Dembroski TM, Weiss SM, Shields JL, Haynes SG, Feinleib M).pp. 55-69. New York: Springer, 1978.

5. Jenkins CD, Zyzanski SJ, Rosenman RH. Progress toward validation of a computer-scored test for the Type A coronary-prone behavior pattern. Psychosom Med 1971; 33: 193-202.

6. Johnston DW, Shaper AG. Type A behavior in British men: reliability and intercorrelation of two measures. J chron Dis 1983; 36: 203-207.

7. Myrtek M, Schmint TH, Schwab G. Untersuchungen zur Reliabilität und Validität der deutschen Version des Jenkins Activity Survey (JAS). Z Klin Psychol 1984; in press.

8. LACEY JI, LACEY BC. The law of initial value in the longitudinal study of autonomic constitution: reproducibility of autonomic responses and response pattern over a four ycar interval. Ann NY Acad Sci 1962; 98: 1257-1290.

9. Dembroski TM. Reliability and validity of methods used to assess coronary-prone behavior. In: Coronary Prone Behavior (Edited by Dembroski TM, Weiss SM, Shields JL, Haynes SG, Feinleis M) 95-106. New York: Springer, 1978.

10. Dembroski TM, Mac Dougall JM. Behavioral and psychophysiological perspectives on coronaryprone behavior. In: Biobehaviaral Bases of Coronary Heart Disease (Edited by Demproski TM, Schmidt TH, BlümcheN G). Basel: Karger, 1983.

\section{APPENDIX}

List of studies used on the issue of physiological differences between Type $A$ and $B$

Blumenthal JA, MCKeE DC. Task incentives, Type A behavior pattern, and verbal problem solving performance. J Appl Soc Psychol 1980; 10: 101-114.

Blumenthal JA, MCKe DC, Williams RB, Haney T. Assessment of conceptual tempo in the Type A (coronary prone) behavior pattern. J Pers Assess 1981; 45: 44-51.

Blumenthal. JA, Willings RS, Williams RB, Wallace AG. Effect of exercise on the Type A (coronary prone) behavior pattern. Psychosom Med 1980; 42: 289-296.

Brodner G, Langosch W, Farinelli E. The Type A bchavior pattern applied to problems in the rehabilitation of Ml-patients below age 40: associations with personality dimensions and psychophysiological parameters essential to CHD. Activ Nerv Sup 1982; (Suppl. 3), 163-167.

Carver CS, Coltman AE, Glass DC. The coronary-prone behavior pattern and the suppression of fatigue on a treadmill test. J Pers Soc Psychol 1976; 33: 460-466.

De Backer G, Kornitzer M, Kittel F, Bogaert M, Van Durme JP, Vincke J, Rustin RM, Degré C, DE SCHAFPDRIJVF A. Relation between coronary-prone behavior pattern, excretion of urinary catecholamines, heart rate, and heart rhythm. Prev Med 1979; 8: 14-22.

Dembroski TM, MacDougall JM, Herd JA, Shields JL. Effects of level of challenge on pressor and heart rate responses in Type A and B subjects. $J$ Appl Psychol 1979; 9: 209-228. 
Dembroski TM, MacDougall JM, Lushene R. Interpersonal interaction and cardiovascular response in Type A subjects and coronary patients. J Hum Stress 1979; 5: $28-36$.

Dembroskı TM, MacDolgall JM, Shields JL. Physiologic reactions to social challenge in persons evidencing the Type A coronary-prone behavior pattern. J Hum Stress 1977; 3: 2-9.

Dembroski TM, MacDougall JM, Shields JL, Petitro J, Lushene R. Components of the Type A coronary-prone behavior pattern and cardiovascular responses to psychomotor performance challenge. J Behav Med 1978; 1: 159-176.

Diamond EL, CARver CS. Sensory processing, cardiovascular reactivity, and the Type A coronaryprone behavior pattern. Biol Psychol 1980; 10: 265-275.

Von Eiff AW, Friedrich G, Neus H, Rüddel H, Schmieder R. Effects of $\beta$-blockers on Type-A coronary-prone behaviour. Klin Wschr 1982; 60: 1315-1316.

Frankenhaeuser M, Lundberg U, Forsman L. Note on arousing Type A persons by depriving them of work. J Psychosom Res 1980; 24: 45-47.

IRANkenhaeuser M, Lundherg U, Forsman I. Dissociation between sympathetic-adrenal and pituitaryadrenal responses to an achievement situation characterized by high controllability: comparison between Type A and Type B males and females. Biol Psychol 1980a; 10: 79-91.

Friedman EH, Heilerstein HK, Eastwood GL, Jones SE. Behavior patterns and serum cholesterol in two groups of normal males. Am J Med Sci 1968; 255: 237-244.

Friedman M, Byers SO, Rosenman RH, Elevitch FR. Coronary-prone individuals (Type A behavior pattern): some biochemical characteristics. JAMA 1970; 212: 1030-1037.

Iriedman M, Rosenman RH, George SS. Adrenal response to excess corticotropin in coronary-prone men. Proc Soc Exp Biol Med 1969; 131: 1305-1307.

GAstorf JW. Physiologic reaction of Type A's to objective and subjective challenge. J Hum Stress $1981 ; 7: 16-20$.

Giass DC, Krakoff lR, Contrada R, Hilton WF, Kehoe K, Mannucci EG, Collins C, Snow B, EITING E. Effect of harassment and competition upon cardiovascular and plasma catecholaminc responses in Type A and Type B individuals. Psychophysiology 1980; 17: 453-463.

Goldband S. Stimulus specificity of physiological response to stress and the Type A coronary-prone behavior pattern. J Pers Soc Psychol 1980; 39: 670-679.

HASHImoto T. Effects of control on cardiovascular changes and coronary-prone behavior pattern. Jap J Psychol 1981; 51: 356-359.

Holmes DS, Solomon S, Rump BS. Cardiac and subjective response to cognitive challenge and to controlled physical exercise by male and female coronary prone (Type $\mathrm{A}$ ) and non-coronary prone persons. J Psychosom Res 1982; 26: 309-316.

Howard JH, Cunningham DA, Rechnitzer PA. Health patterns associated with Type A behavior: a managerial population. J Hum Stress 1976; 2: 24-31.

Ivancevich JM, Matteson MI, Preston C. Occupational stress, Type A behavior, and physical well bcing. Acud Management $J$ 1982; 25: 373-391.

Jennings JR, ChoI S. Type A components and psychophysiological responses to an attention-demanding performance task. Psychosom Med 1981; 43: 475-487.

JORGENSEN RS, Houston BK. The Type A bchavior pattern, sex differences, and cardiovascular response to and recovery from stress. Motiv Emot 1981; 5; 201-213.

Kahn JP, Kornfeld DS, Frank KA, Heller SS, Hoar PF. Type A behavior and blood pressure during coronary artery bypass surgery. Psychosom Med 1980; 42: 407-414.

Krantz DS, Schaeffer MA, Davia JE, Dembroski TM, MacDolgall JM, Shaffer RT. Extent of coronary atherosclerosis, Type A behavior, and cardiovascular response to social interaction. Psychophysiology 1981; 18: 654-664.

LANGOSCH W, Brodnfr G, Farinele E. Type A behavior pattern in a German sample of post infarction patients below age 40. Activ Nerv Sup 1982; (Suppl. 3), 157-162.

LAWI.FR KA, AlLen MT, CRITCher EC, STANDARD BA. The relationship of physiological responses to the coronary-prone behavior pattern in children. I Behav Med 1981; 4: 203-216.

Lot GG, Gatchel RJ. A multi-response analysis of learned heart rate control. Psychophysiology 1978; 15: $576-581$.

Lovallo WR, Pishkin V. A psychophysiological comparison of Type A and B men exposed to failure and uncontrollable noise. Psychophysiology 1980; 17: 29-36.

LlNdierg U, Forsman L. Adrenal-medullary and adrenal-cortical responses to understimulation and overstimulation: comparison between Type A and Type B persons. Biol Psychol 1979; 9: 79-89.

MacDougall JM, Dembroski TM, Krantz DS. Effects of types of challenge on pressor and heart rate responses in Type A and B women. Psychophysiology 1981; 18: 1-9.

Manuck SB, CRAfT S, Gold KJ. Coronary-prone behavior pattern and cardiovascular response. Psychophysiology 1978; 15: 403-411.

ManUCK SB, GARland FN. Coronary-prone behavior pattern, task incentive, and cardiovascular response. Psychophysiology 1979; 16: 136-142. 
Pittner MS, Hotston BK. Response to stress, cognitive coping strategies, and the Type A behavior pattern. J Pers Soc Psychol 1980; 39: 147-157.

PRICE KP, CLARKE LK. Behavioral and psychophysiological correlates of the coronary-prone personality: new data and unanswered questions. $J$ Psychosom Res 1978; 22: 409-417.

Scherwitz L, Berton K, Leventhal H. Type A behavior, self-involvement, and cardiovascular response. Psychosom Med 1978; 40: 593-609.

Schmid TH, Undeutsch K, Dembroski TM, Langosch W, Nels H, Rïddel. H. Coronary prone behavior and cardiovascular reactions during the German version of the Type A interview and during a quiz. Activ Nerv Sup 1982; (Suppl. 3), 241-251.

Simpson MT, Olewine DA, Jenkins CD, Ramsey FH, Zyzanski SJ, Thomas G, Hames CG. Exerciseinduced catecholamines and platelet aggregation in the coronary-prone behavior pattern. Psychosom Med 1974; 36: 476-487.

Steptoe A, Ross A. Psychophysiological reactivity and the prediction of cardiovascular disorders. $J$ Psychosom Res 1981; 25: 23-31.

VAN EGEREN LF. Social interactions, communications, and the coronary-prone behavior pattern: a psychophysiological study. Psychosom Med 1979; 41: 2-18.

Williams RB, Kuhn CM, Melosh W, White AD, Schasiberg SM. Type A behavior and elevated physiological and neuroendocrine responses to cognitive tasks. Science $1982 ; 218: 483-485$.

YARNOLD PR, GRimM LG. Time urgency among coronary-prone individuals. J Abnorm Psychol 1982; 91: $175-177$.

\section{List of studies used concerning reliability of and agreement between SI and JAS}

Appels $\Lambda$, Jenkins CD, Rosenman RH. Coronary-prone behavior in the Netherlands: a eross-cultural validation study. I Behuv Med 1982; 5: 83-90.

Bllmenthal JA, Mckee DC. Task incentives, Type A behavior pattern, and verbal problem solving performance. $J$ Appl Soc Psychol 1980; 10: 101-114.

CAFFREY B. Reliability and validity of personality and bchavioral measures in a study of coronary heart disease. J chron Dis 1968; 21: 191-204.

Chesney MA, Black GW, Chadwick JH, Rosenmas RH. Psychological correlates of the coronaryprone behavior pattern. J. Behav Med 1981; 4:217-230.

Friedman EH, Hellerstein HK, Eastwood GL, Jones SE. Behavior patterns and serum cholesterol in two groups of normal males. Am J Med Sci 1968; 255: 237-244.

Ivanceyich JM, Matteson MT, Preston C. Occupational stress, Type A behavior, and physical well being. Acad Management J 1982; 25: 373-391.

Jenkins CD, Rosenman RH, Friedman: M. Development of an objective psychological test for the determination of the coronary-prone behavior pattern in employed men. J chron Dis 1967; 20: 371 - 379.

JENkins CD, Zyzanski SJ, Rosenman RH. Progress loward validation of a computer-scored test for the Type A coronary-prone behavior pattern. Psychosom Med 1971; 33: 193-202.

Keith RA, Lowv B, Stare FJ. Coronary heart disease and behavior patterns. Psychosom Med 1965; 27: 424-434.

Kittel F, Kornitzer M, Zyzanski SJ, Jenkins CD, Rusiin RM, Degre C. Two methods of assessing the Type A coronary-prone behavior pattern in Belgium. J chron Dis 1978; 31: 147-155.

MacDougall JM, Dembroski TM, Musante $L$. The structured interview and questionnaire methods of assessing coronary-prone behavior in male and female college students. J Behav Med 1979; 2: 7I-83.

Matthfws KA, KRantz DS, Dembroskj TM, MacDougall JM. Unique and common variance in structured interview and Jenkins Activity Survey measures of the Type $\Lambda$ behavior pattern. $J$ Pers Soc Psychol 1982; 42: 303-313.

MATTHEws KA, SAAI. FE. Relationship of the Type A coronary-prone behavior pattern to achievement, power, and affiliation motives. Psychosom Med 1978; 40: 631-636.

Myrtek M, Schmin TH, Schwab G. Untersuchungen zur Reliabilität und Validität der deutschen Version des Jenkins Activity Survey (JAS). Z Klin Psychol 1984; in press.

Raht: RH, HeRvig L, Rosenman RH. Heritability of Type A behavior. Psychosom Med 1978; 40: 478-486.

SChERwitz L, Berton K, LeVenthal H. Type A assessment and interaction in the behavior pattern interview. Psychosom Med 1977; 39: 229-240.

Schmidt TH, Undeutsch K, Iembroski TM, Langosch W, Neus H, Rüddel H. Coronary prone behavior and cardiovascular reactions during the German version of the Type $A$ interview and during a quiz. Activ Nerv Sup 1982; (Suppl. 3), 241-251.

Verhagen F, Nass C, Appels A, Van Bastelatik A, Winnubst J. Cross-validation of the A/B typology in the Netheriands. Psychother Psychosom 1980; 34: 178-186.

Vickers RR, HeRvig LK, RaHe RH, Rostinman RH. Type A behavior pattern and coping and defense. Psychosom Med 1981; 43: 381-396. 